\title{
Ultra-wideband Antenna for WLAN, WiMAX and LTE Applications
}

\author{
Shubhanshi Rathore \\ M. Tech Scholar \\ ECE Department \\ SHIATS-DU \\ Allahabad, U.P., India
}

\author{
Rajeev Paulus \\ Assistant Professor \\ ECE Department \\ SHIATS-DU \\ Allahabad, U.P., India
}

\author{
A.K. Jaiswal \\ Professor, H.O.D. \\ ECE Department \\ SHIATS-DU \\ Allahabad, U.P., India
}

\author{
Aditi Agrawal \\ Assistant Professor \\ ECE Department \\ SHIATS-DU \\ Allahabad, U.P., India
}

\begin{abstract}
A compact ultra-wideband antenna (UWB) is presented in this paper for WLAN, WiMAX, LTE and Smart grid applications. The proposed antenna comprises a circular patch and rectangular slot in center of circular patch and apart from this it also consists of four small rectangular slots around circular patch to provide wideband. The antenna is fabricated onto Rogers R03003 substrate with an overall dimension of 47X47 $\mathrm{mm}^{2}$. The substrate has dielectric constant of 3 and thickness of $1.6 \mathrm{~mm}$. The simulated experiment shows that the proposed antenna achieves good impedance matching an operating bandwidth of $2.5-8.2 \mathrm{GHz}(106.5 \%)$ and $10-15 \mathrm{GHz}(40 \%)$ that covers the lower UWB and higher UWB band. Thus it covers WLAN 5.2/5.8 GHz band, WiMAX 2.5/3.5/5.5 GHz band and LTE $2.5-2.69 \mathrm{GHz}$ band. The gain of this antenna varies between 2-3 $\mathrm{dBi}$ for most of the frequency band and therefore the proposed antenna is suitable for being used in UWB communication applications.
\end{abstract}

\section{Keywords}

Ultra-wideband antenna, WLAN, WiMAX, LTE and CST Microwave Studio.

\section{INTRODUCTION}

Ultra-wideband (UWB) technology have attractive characteristics like low cost, low complexity, low spectral power density, high data resolution, very low interference, and extremely high data transmission rates which made it suitable for various wireless communications [1]. For different wireless communication applications, a UWB antenna must be electronically small and inexpensive without degrading the performance. Designing of an efficient and low-profile UWB antenna to match the applications such as stable Omni directional radiation patterns, gain flatness, and linear phase variation which are required to fulfill the demands of UWB applications is still a major challenge. Apart from this one serious limitation of the microstrip antenna was its narrow bandwidth characteristics, being 15 to $50 \%$ that of commonly used antenna elements such as dipoles, slots, and waveguides horns [2]. This limitation was successfully removed by achieving a required matching impedance bandwidth ratio and for that it was necessary to increase the size, height, volume or feeding and matching techniques [3]. Recently many research papers have been published which cover wideband and given many techniques to achieve ultra-wideband [4-9].

UWB have wide applications in short range and high speed wireless systems, such as ground penetrating radars, medical imaging system, high data rate wireless local area networks (WLAN), communication systems for military and short pulse radars for automotive or robotics. The antenna is one of the crucial components, which determines the performance of UWB system [10].

Generally, UWB communication antennas require low Voltage Standing Wave Ratio $(\mathrm{VSWR}<2$ ), constant phase center, constant group delay, and constant gain over entire operating frequency band [11]. In this paper, an UWB patch antenna has been proposed with optimized dimensions which give good return loss, VSWR, gain, and desired bandwidth. The antenna consists of a circular patch and wide slot cut in the center of circular patch. The antenna is fed with $50 \Omega$ microstrip line through coplanar waveguide structure. This antenna is easy to integrate with microwave circuitry for low manufacturing cost [12]. In recent years coplanar waveguide fed antennas are being extensively investigated [13-14]. The coplanar waveguide, compared with the microstrip line, has advantages such as low radiation loss, less dispersion; uniplanar configuration and easy mounting of shunt lumped elements or active devices [15]. The design of antenna is simulated in CST Microwave Studio for obtaining the optimum dimensions of the antenna. The rest of the paper is organized as follows: Section 2 describes the antenna design, Computer Simulation Technology results are presented in section 3 and finally Section 4 concludes the paper.

\section{ANTENNA DESIGN}

The proposed design of UWB antenna is simple and compact that introduces low distortions with impedance bandwidth of $106.6 \%$ for first band $(2.5-8.2 \mathrm{GHz})$ and impedance bandwidth of $40 \%$ for second frequency band (10-15 GHz). The geometric configuration of the proposed antenna is shown in figure 1 . The antenna consists of a circular patch with wide slot in centre of the patch on one side of antenna substrate where it consists of rectangular patch in ground plane on other side of substrate. The entire antenna structure was designed on Rogers RO3003 substrate with dielectric constant of 3 and thickness of $1.6 \mathrm{~mm}$. Rogers RO3003 is chosen for dielectric material as it is performance sensitive and it offer superior high frequency performance with low 
cost fabrication. The front design of the proposed antenna consists of circular patch with radius $12.5 \mathrm{~mm}$. This dimension is chosen in order to get resonance around 3.5 $\mathrm{GHz}$. Apart from this two type of slot is cut into circular patch first slot rectangular slot in the centre of patch with $52 \mathrm{~mm}$ of perimeter this provide resonance of antenna around $5.7 \mathrm{GHz}$.

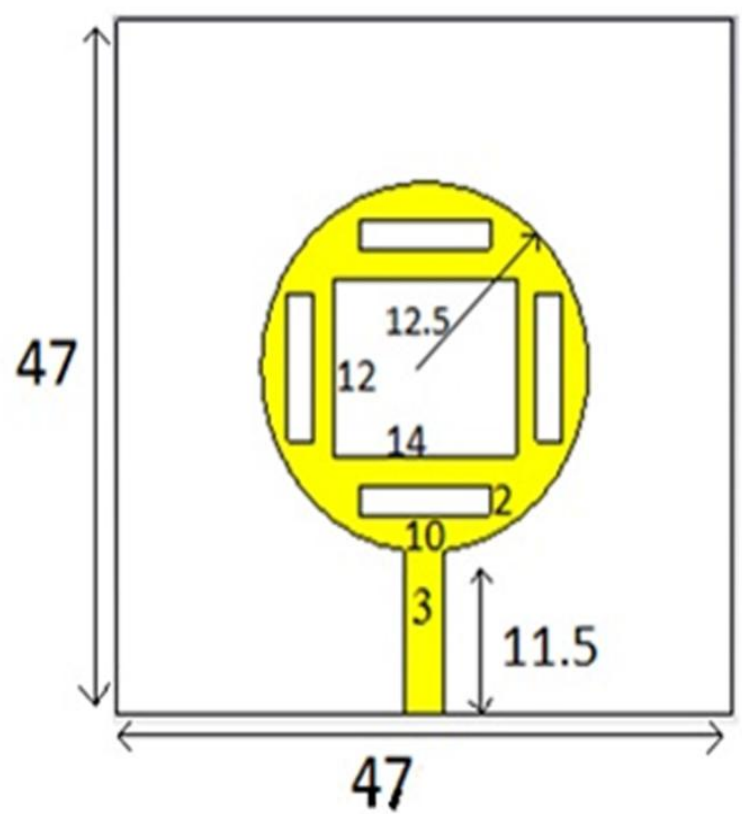

Top view

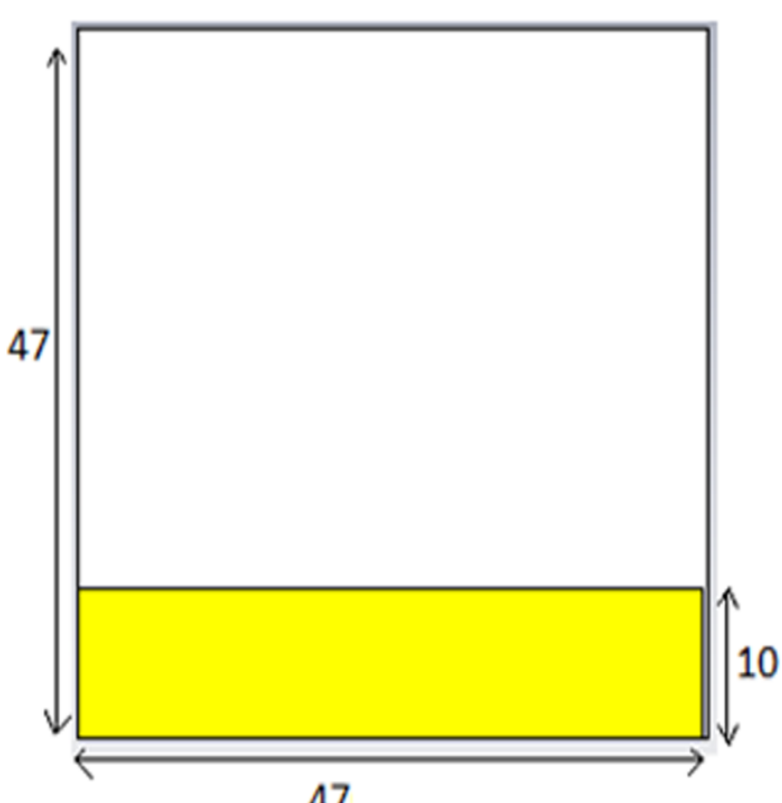

Bottom view

Fig 1: Geometry of antenna

Other slot is around the bigger slot with perimeter of $24 \mathrm{~mm}$ this is to provide additional electrical path so that antenna can resonate at higher frequency. Back design consist of the ground plane with $47 \times 10 \mathrm{~mm}$ of rectangular patch, this ground plane dimension have seen selected after number of trials in simulation software to get better impedance match in desired frequency band. It is to be noted that all the dimensions shown in figure 1 is in $\mathrm{mm}$.

Table 1. Dimensions of the Proposed Antenna

\begin{tabular}{|c|c|}
\hline Substrate Length & $47 \mathrm{~mm}$ \\
\hline Substrate Width & $47 \mathrm{~mm}$ \\
\hline Substrate Thickness & $1.6 \mathrm{~mm}$ \\
\hline Circular Patch Radius & $12.5 \mathrm{~mm}$ \\
\hline Wide Rectangular Slot Length & $12 \mathrm{~mm}$ \\
\hline Wide Rectangular Slot Width & $14 \mathrm{~mm}$ \\
\hline Small Rectangular Slots Length & $2 \mathrm{~mm}$ \\
\hline Small Rectangular Slots Width & $10 \mathrm{~mm}$ \\
\hline $\begin{array}{c}\text { Coplanar Waveguide Feed line } \\
\text { Length }\end{array}$ & $11.5 \mathrm{~mm}$ \\
\hline $\begin{array}{c}\text { Coplanar Waveguide Feed line } \\
\text { Width }\end{array}$ & $3 \mathrm{~mm}$ \\
\hline
\end{tabular}

\section{RESULTS AND DISCUSSION}

In this paper CST Microwave Studio is used for the design, simulation and analysis of the proposed antenna. Figure 2 shows the $S_{11}$ parameter of the proposed antenna and it has good impedance match over two bands $(2.5-8.2 \mathrm{GHz})$ and $(10-15 \mathrm{GHz})$ with reflection coefficient less than $-10 \mathrm{~dB}$. The first band has bandwidth of $5.7 \mathrm{GHz}$ with maximum return loss of $-37 \mathrm{~dB}$ at $5.2 \mathrm{GHz}$ and second band is of $5 \mathrm{GHz}$ with maximum return loss of $-47 \mathrm{~dB}$ at $13.7 \mathrm{GHz}$ by implementing the optimum dimensions of the CPW feed and the rectangular shaped slot in center of circular patch.

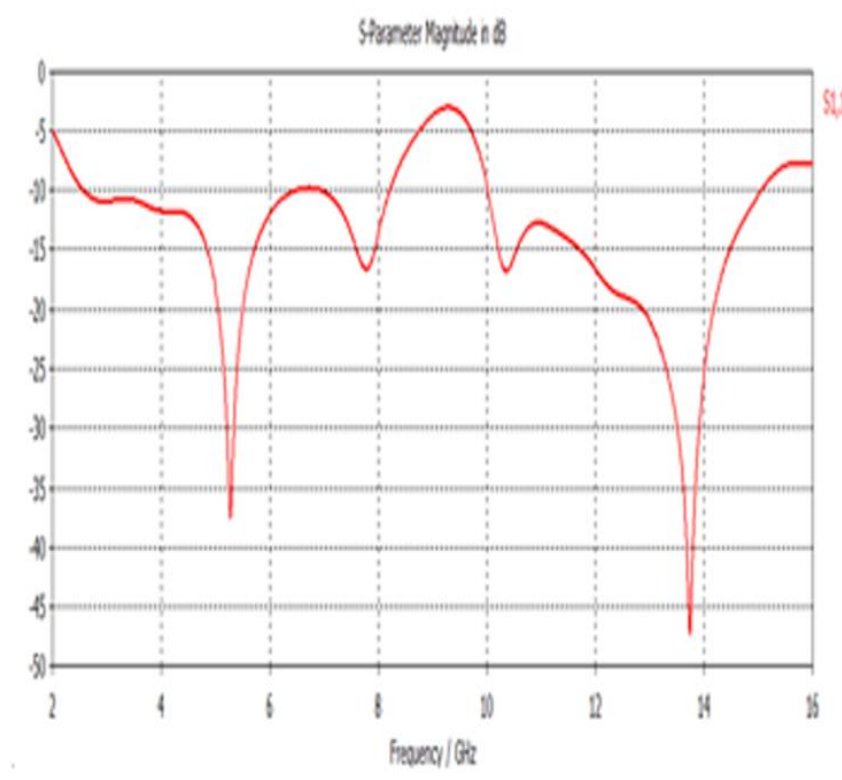

Fig 2: Simulated $S_{11}$ parameter of proposed UWB antenna

Figure 3 shows the VSWR magnitude of the antenna which is fairly below 2 for the frequencies in which antenna is resonating. The VSWR of the antenna is closely related to the return loss. VSWR varies from 1 to 2 throughout the frequency region i.e. $2.5-8.2 \mathrm{GHz}$ and $10-15 \mathrm{GHz}$, except from $8.3 \mathrm{GHz}$ to $9.9 \mathrm{GHz}$. Since UWB characteristic requires the VSWR to be in the range of 1 to 2 , the frequency region from $8.3 \mathrm{GHz}$ to $9.9 \mathrm{GHz}$ for the measured result does not agree with the UWB characteristic. Based on the simulated results, the proposed antenna exhibits good UWB characteristics and operates from $2.5 \mathrm{GHz}-8.2 \mathrm{GHz}$, and 10-15 
$\mathrm{GHz}$, having impedance bandwidth of $106.5 \%$ and $40.0 \%$ respectively. It complies with the VSWR range from 1 to 2 throughout the impedance bandwidth.

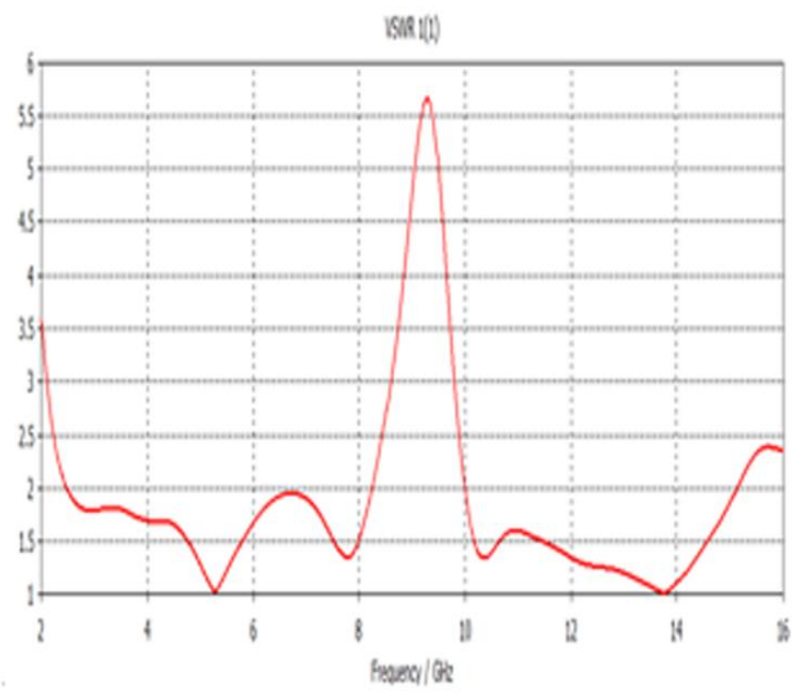

Fig 3: Simulated VSWR of proposed antenna

Figure 4 shows the radiation pattern of antenna at $5 \mathrm{GHz}, 8$ $\mathrm{GHz}, 9 \mathrm{GHz}$ and $14 \mathrm{GHz}$.
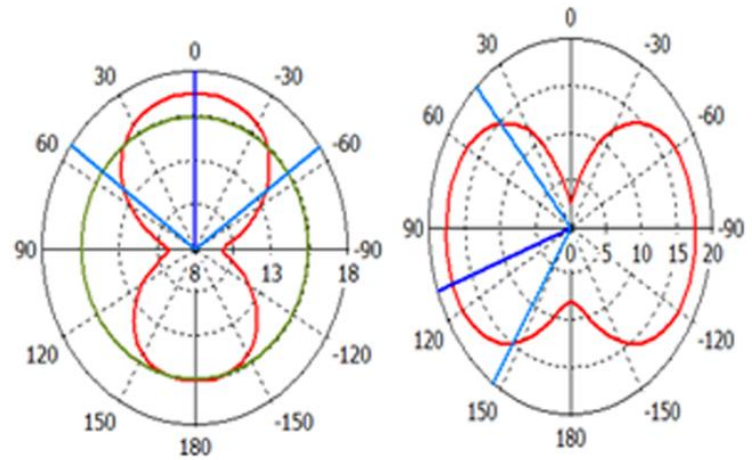

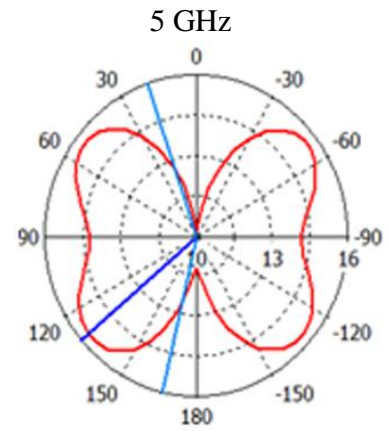

$9 \mathrm{GHz}$

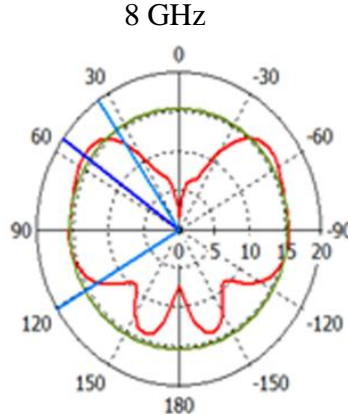

$14 \mathrm{GHz}$
Fig 4: Simulated radiation pattern of the proposed antenna at $5 \mathrm{GHz}, 8 \mathrm{GHZ}, 9 \mathrm{GHz}$ and $14 \mathrm{GHz}$

From the figure it clear that radiation pattern of antenna is almost Omni directional for most of the frequency in the desired frequency band. At some frequency the radiation is not Omni directional this is because impedance match is function of frequency and it is very difficult maintain impedance match and desired radiation pattern. At specific frequency if radiation pattern is Omni directional then same antenna at higher frequency will not have the Omni directional radiation pattern this because the wavelength for higher frequency have changed. Well in this proposed design we try to maintain Omni directional pattern for the most of frequency since UWB antenna are used in home and industry where prime requirement is Omni directional pattern. In this design slot were introduced within circular patch to provide different electrical path within antenna. So that it can resonate at different frequency and with desired radiation pattern.

Figure 5 shows the gain of the proposed antenna. From the figure it is noticed that the gain of antenna varies between 2 to $3 \mathrm{dBi}$ for the most of frequency and with the maximum gain of $3.4 \mathrm{dBi}$ at $8.2 \mathrm{GHz}$.

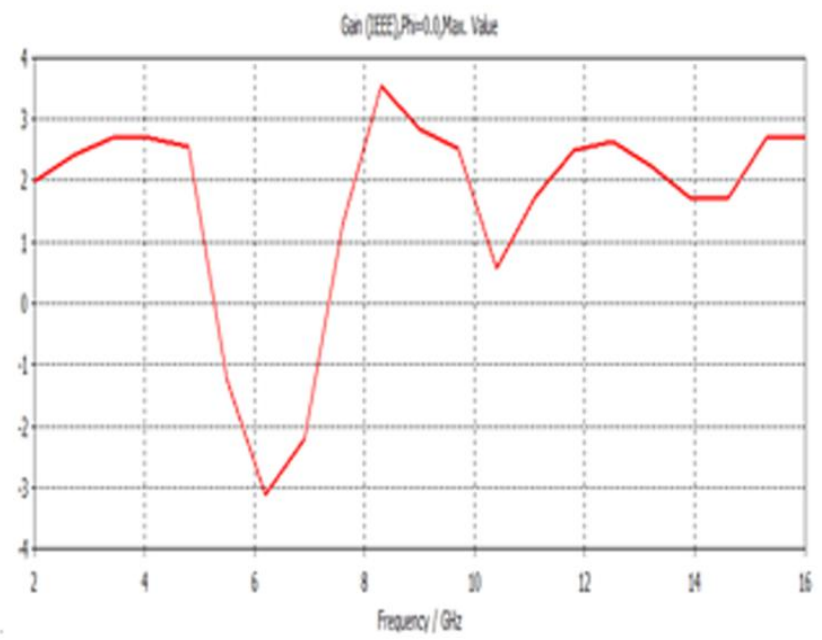

Fig 5: Simulated gain of proposed antenna

\subsection{Results Comparison}

The simulated results of the proposed antenna shows that it has quite good large bandwidth which is better than UWB antenna paper published earlier, paper [16] shows that it covers impedance bandwidth of $46.6 \%$ for the first band (5.82-8.8 $\mathrm{GHz})$ and $41.32 \%$ for the second band $(10.8-15.8 \mathrm{GHz})$ only.

Table 2. Comparison of Results

\begin{tabular}{|c|c|c|}
\hline Parameters & $\begin{array}{c}\text { Proposed } \\
\text { Antenna }\end{array}$ & Paper [16] \\
\hline \multirow[t]{2}{*}{ Bandwidth } & $\begin{array}{l}2.5-8.2 \mathrm{GHz} \text { (first } \\
\text { band) }\end{array}$ & $\begin{array}{l}5.82-8.8 \\
\text { (first band) }\end{array} \mathrm{GHz}$ \\
\hline & $\begin{array}{l}10-15 \mathrm{GHz} \text { (second } \\
\text { band) }\end{array}$ & $\begin{array}{l}10.8-15.8 \mathrm{GHz} \\
\text { (second band) }\end{array}$ \\
\hline \multirow{2}{*}{$\begin{array}{l}\text { Impedance } \\
\text { Bandwidth }\end{array}$} & $106.6 \%$ (first band) & $\begin{array}{l}46.6 \% \quad \text { (first } \\
\text { band) }\end{array}$ \\
\hline & $40 \%$ (second band) & $\begin{array}{l}41.32 \% \text { (second } \\
\text { band) }\end{array}$ \\
\hline VSWR & $\begin{array}{l}2.5-8.2 \mathrm{GHz} \text { and } \\
10-15 \mathrm{GHz}\end{array}$ & $\begin{array}{l}3.9 \mathrm{GHz}, 5.82- \\
8.8 \mathrm{GHz} \text { and } \\
10.8-15.8 \mathrm{GHz}\end{array}$ \\
\hline
\end{tabular}




\section{CONCLUSION}

A coplanar waveguide fed microstrip patch antenna design and simulation in CST Microwave Studio has been presented in this paper with gain of $3.4 \mathrm{dBi}$ and appreciable value of return loss of $-37 \mathrm{~dB}$ at $5.2 \mathrm{GHz}$ and $-47 \mathrm{~dB}$ at $13.7 \mathrm{GHz}$. The dimension of antenna is $47 \times 47 \times 1.6 \mathrm{~mm}^{3}$.The simulated results of the proposed antenna satisfy the $-10 \mathrm{~dB}$ return loss requirements for UWB as defined by the FCC. The characteristics of the proposed antenna such as good coverage and stable transmission indicate that the proposed compact antenna is well suitable for integration into UWB portable devices. The proposed antenna fulfills the requirement of WLAN (5.2/5.8 GHz), WiMAX (2.5/3.5/5.5 GHz) and LTE $(2.5-2.69 \mathrm{GHz})$. The antenna can also be used in smart grid technology (11-18 GHz) and in European fixed satellite systems which have appreciable gain in $12-14 \mathrm{GHz}$ band of frequencies.

\section{REFERENCES}

[1] Chen, H. D., 2003, "Broadband CPW-fed square slot antennas with a widened tuning stub," IEEE Trans. Antennas Propag., vol. 51, no. 8, pp. 1982-1986.

[2] Solis, M. A. P., Galvan-Tejada, G. M. and JardonAguilar, H., 2005, "State of the Art in Ultra-Wideband Antennas," in 2nd International IEEE Conference on Electrical \& Electronics and XI Conference on Electrical Engineering, pp. 101-105.

[3] Garg, R., Bhartia, P., Bahl, I., and Ittipiboon, A., 2001, "Microstrip Antenna Design Handbook," Ed. Artech House, ch. 9, pp. 53.

[4] Roshan, R., Pandey, U. and Singh, R. K., 2014, "Dual Wideband Planer Monopole Antenna for Mobile and WiFi/WLAN Application," IEEE Conference at SCES2014.

[5] Roshan, R., and Singh, R. K., 2014, "Dual ISM Band MIMO Antenna for WiFi and WiMax Application," IEEE Conference at ICSPCT 2014.

[6] Jan, J. Y., and Su, J.W., 2005, "Bandwidth enhancement of a printed wide-slot antenna with a rotated slot," IEEE Trans. Antennas Propag., vol. 53, no. 6, pp. 2111-2114.
[7] Qu, S.W., Ruan, C., and Wang, B. Z., 2006, "Bandwidth enhancement of wideslot antenna fed by CPW and microstrip line," IEEE Antennas Wireless Propag. Lett., vol. 5, pp. 15-17.

[8] See, C. H., Abd-Alhameed, R. A., Abidin, Z. Z., McEwan, N. J. and Excell, P. S., 2012, "Wideband Printed MIMO/Diversity Monopole Antenna for WiFi/WiMAX Applications," IEEE Trans. Antennas and propagation, vol. 60. No. 4, pp. 2028-2034.

[9] Zhang, S., Ying, Z., Xiong, J. and He, S., 2009, "Ultrawideband MIMO/diversity antennas with a treelike structure to enhance wideband isolation," IEEE Antennas Wireless Propag. Letter, vol. 8, pp. 12791282.

[10] Azim, R., Mobashsher, A. T., Norbahiah Misran, M. T. I. N., 2010, "Compact Planar Antenna for UWB Applications," in ICMMT 2010 Proceedings.

[11] Sobli, N. M. and Abd-El-Raouf, H. E., 2008, "Design of a Compact Band-Notched Antenna for Ultrawideband Communication," IEEE Antennas and propagation symposium APS2008.

[12] Y.S., Yang, X.D., Liu, C.Y., and Jiang, T., "Compact CPW-fed Ultrawideband antenna with band-notched characteristic," Electronic Lett., 2010, 46, (23), pp. $1533-1534$.

[13] Abed, D., Kampuchea, H., and Atrouz, B., 2008, "Smallsize printed CPW- Fed antenna for ultra-wideband communications," Electron. Lett. 2008, 44,(17), pp. $1003-1005$.

[14] Agrawall, N. P., Kumar, G., and K. P. Ray, K. P., 1998, "Wide-band planar monopole antennas," IEEE Trans. Antennas and Propagation, vol. 46, no. 2, pp. 294-295.

[15] Vyas, K., Sharma, A. K. and Singhal, P. K., 2012, “A Novel CPW Fed Multiband Circular Microstrip Patch Antenna for Wireless Applications," IEEE Conference on Computer Intelligence and Communication Networks (CICN) 2012 